Agro-Science Journal of Tropical Agriculture, Food, Environment and Extension Volume 10 Number 3 Sentember 2011 nn $38-42$

ISSN 1119-7455

\title{
FACTORS THAT INFLUENCE IRON STATUS OF PREGNANT WOMEN IN NSUKKA LOCAL GOVERNMENT AREA OF ENUGU STATE, NIGERIA.
}

\author{
Eze S.N. and Okeke E.C. \\ Department of Home Science, Nutrition and Dietetics, University of Nigeria, Nsukka, \\ Nigeria.
}

\begin{abstract}
Iron deficiency, the commonest nutritional disorder worldwide, has serious impact on pregnant women. The prevalence of anaemia among pregnant women in Africa ranges from $47 \%$ in East Africa to $56 \%$ in West Africa. Among Nigerian women, South-eastern Nigeria has the highest prevalence $(61 \%)$ of iron deficiency anaemia. The study investigated the factors that influence iron status of pregnant women in Nsukka Local Government Area of Enugu State, Nigeria. The respondents comprised 386 pregnant women randomly selected in Nsukka Local Government Area. A validated structured questionnaire was used to collect information on respondents' socioeconomic and obstetric characteristics. Determination of haemoglobin concentration $(\mathrm{Hb})$ was used to assess the respondents' iron status. The result showed that less than half (44.1\%) of the respondents had normal iron status, while $55.9 \%$ of the respondents had varying degrees of iron deficiency. Mean $\mathrm{Hb}$ of the respondents was $10.87 \pm 0.99 \mathrm{~g} / \mathrm{dl}$. Iron status of the respondents was significantly $(P<0.05)$ influenced by age, occupation, educational and income levels. Respondents below 20 years had significantly lower $\mathrm{Hb}(\boldsymbol{P}<0.05)$ than other ages. Artisans, farmers and traders had significantly lower $\mathrm{Hb}(P<0.05)$ than other occupational groups. Hb significantly increased with increase in educational and income levels $(P<0.05)$. Women's nutritional/health status hinges on improved educational/economic empowerment, and is further impaired by early marriage and teenage pregnancy. Women's education must be highly prioritized, and community-based approaches employed for promotion of girl-child education and prevention of adolescent marriage/pregnancy. More income generating activities/entrepreneurial skills for women are imperative to boost their income and spending on family food.
\end{abstract}

Key words: iron status, influencing factors, pregnant women, Nsukka.

\section{INTRODUCTION}

Malnutrition is one of the major problems in the developing world today. It perpetuates itself generation by generation. Globally, malnutrition is the most important risk factor for illness and death, and affects millions of pregnant women and young children in particular. Pregnant women are vulnerable to malnutrition due to their increased nutrient needs coupled with the social and biological stresses they face. They exercise roles in reproduction, economic production and home production, often with damaging consequences for their own nutritional status (Administrative Committee on Coordination/ Subcommittee on Nutrition [ACC/SCN], 1990).

Iron deficiency, the commonest nutritional disorder in both developed and developing countries, has serious impact on pregnant women. The prevalence of anaemia among pregnant women in Africa ranged from $47 \%$ in East Africa to $56 \%$ in West Africa
(ACC/SCN, 2000). The results of the 2001 2003 Nigeria food consumption and nutrition survey showed that approximately $35.3 \%$ of pregnant women had varying degrees of iron deficiency (Maxiya-Dixon et al., 2004). Among Nigerian women, South-eastern Nigeria had the highest prevalence $(61 \%)$ of iron deficiency anaemia (Federal Government of Nigeria [FGN]/ UNICEF, 1994).

There are numerous reports on the effects of iron deficiency in pregnancy. For instance, higher perinatal maternal mortality among women with low haemoglobin concentration was reported in Zaria, Nigeria (Harrison, 1982). It is estimated that 52,900 Nigerian women die annually from pregnancy related complications (Federal Ministry of Health [FMOH], 2008). This represents $10 \%$ of global maternal deaths, whereas Nigeria constitutes only $1 \%$ of the world population. A woman's chance of dying from pregnancy and 
childbirth in Nigeria is in a ratio of 1: 13 (FMOH, 2008). The risk of haemorrhage, the commonest cause of maternal death (ACC/SCN, 1992), could be minimized by prevention of anaemia, and it has been shown that iron deficiency is responsible for $90 \%$ cases of anaemia in developing countries (ACC/SCN, 1991).

Iron deficiency anaemia in pregnancy was also linked with low birth weight both in pre- and full term deliveries (Scholl and Hediger, 1994). Higher prevalence of shorter pregnancies/ preterm deliveries was reported among iron deficient women than non-anaemic and even anaemic pregnant women who were not iron deficient (Viteri, 1994). The determination of factors that influence the iron status of pregnant women in Nsukka Local government Area of Enugu State was undertaken as a preliminary study for the alleviation of iron deficiency among pregnant women.

\section{MATERIALS AND METHODS}

The respondents comprised of 386 pregnant women randomly selected from 3 communities (Nsukka urban, Ede-Oballa and Okpuje) in Nsukka Local Government Area of Enugu State, Nigeria. Each community was selected from one development council area of Nsukka Local Government Area. Instruments used for data collection were questionnaire and biochemical analysis of blood samples.

\section{Questionnaire}

A validated structured questionnaire was used to collect data on socio-economic and obstetric characteristics of the respondents. The questionnaire was validated by lecturers in the Department of Home Science, Nutrition and Dietetics, University of Nigeria, Nsukka. To ascertain its clarity, the questionnaire was pretested on 30 ante-natal women in IbagwaAka Cottage Hospital in Igboeze-south Local Government Area of Enugu State. Each item of the questionnaire was explained clearly to the respondents in the language they understood and illiterate respondents were interviewed by trained research assistants.

\section{Biochemical analysis of blood samples}

Determination of haemoglobin concentration was used to assess the iron status of the respondents. Blood samples were collected from $20 \%$ of the respondents for the determination of haemoglobin concentrations. Ethical clearance was obtained from Ethical Committee, Enugu State Ministry of Health prior to the study. Informed consent in a culturally appropriate manner was obtained from all the respondents. The blood sample collections were carefully carried out by phlebotomists following the standard procedure of National Committee for Clinical Laboratory Standards (1991). The blood samples were collected in the non-fasting state by venipunture from the median cubital vein in the antecubital fossa of the fore-arm using sterile syringes and needles. This was done after stabilization and thorough cleansing of the site with $70 \%$ ethanol. The blood samples were collected in tubes with anticoagulant ethylene diamine tetra acetate. Haemoglobin concentrations were determined by cyanmethemoglobin method as described by Butis and Ashwood (1996) in line with International Nutritional Anaemia Consultative Group (1985).

\section{Statistical analysis}

The data collected were analyzed using the Statistical Package for the Social Sciences software (version 17). Data collected were analyzed using descriptive statistics. Duncan's new multiple range tests were used to separate group means, while T-test and analysis of variance were used to compare means. Significant difference was judged at $\mathrm{P}<0.05$.

\section{RESULTS}

Table 1 presents the iron status of the respondents as indicated by their haemoglobin concentrations $(\mathrm{Hb})$. It was shown that less than half $(44.1 \%)$ of the respondents had normal iron status, while $39.0 \%$ and $16.9 \%$ of the respondents had mild and moderate anaemia, respectively. Table 2 presents the respondents' mean haemoglobin concentrations by location and age. The table showed that the iron status of the respondents was not significantly influenced by location $(\mathrm{t}=0.562 ; \mathrm{P}>0.05)$. The mean haemoglobin concentrations of the urban and rural respondents were $10.96 \pm 0.98 \mathrm{~g} / \mathrm{dl}$ and $10.83 \pm 1.00 \mathrm{~g} / \mathrm{dl}$, respectively, while the mean haemoglobin of all the respondents put together was $10.87 \pm 0.99 \mathrm{~g} / \mathrm{dl}$. It was shown that the iron status of the respondents was influenced by age of respondents. Respondents below the age of 20years had significantly lower $\mathrm{Hb} \quad(8.5 \pm$ $0.00 \mathrm{~g} / \mathrm{dl})$ than older respondents $(\mathrm{F}=5.87 ; \mathrm{P}<$ $0.05)$.

Table 1: Frequency and percentage distribution of iron status of the respondents

\begin{tabular}{lll}
\hline Haemoglobin concentration $(\mathbf{g} / \mathbf{d l})$ & $\mathbf{F}$ & $\mathbf{\%}$ \\
\hline Normal (11 \& above) & 34 & 44.1 \\
Mild anaemia $(10.1-10.9)$ & 30 & 39.0 \\
Moderate anaemia $(7-10)$ & 13 & 16.9 \\
Severe anaemia $(<7)$ & - & - \\
Total & $\mathbf{7 7}$ & $\mathbf{1 0 0}$ \\
\hline Key: F: frequency & $\%$ : percentage \\
Source of reference standard: DeMaeyer et al. (1989)
\end{tabular}


Eze S.N. and Okeke E.C.

Table 2: Mean Haemoglobin Concentrations of Respondents by Location and Age.

\begin{tabular}{ll}
\hline Variables & Haemoglobin $\mathbf{( g / d l})$ \\
\hline Location & $10.83^{\mathrm{a}} \pm 1.00$ \\
Rural & $10.96^{\mathrm{a}} \pm 0.98$ \\
Urban & $10.87 \pm 0.99$ \\
Combined & $0.562(0.576)$ \\
T-value (P-value) & \\
Age (years) & $8.50^{\mathrm{b}} \pm 0.00$ \\
$<20$ & $10.98^{\mathrm{a}} \pm 0.85$ \\
$20-25$ & $11.03^{\mathrm{a}} \pm 0.94$ \\
$26-35$ & $10.38^{\mathrm{a}} \pm 1.02$ \\
$36-45$ & $5.87(0.001)$ \\
F-value (P-value) & \\
Key: ab: means with similar superscripts in the same column for each \\
characteristic are not significantly different $(\mathrm{P}>0.05)$ from each other.
\end{tabular}

Table 3: Mean Haemoglobin Concentrations of Respondents by Parity and Trimester.

\begin{tabular}{lc}
\hline Variables & Haemoglobin $(\mathbf{g} / \mathbf{d l})$ \\
\hline Parity & $11.05^{\mathrm{a}} \pm 1.13$ \\
0 & $10.99^{\mathrm{a}} \pm 0.93$ \\
1 to 3 & $10.18^{\mathrm{a}} \pm 0.86$ \\
4 to 6 & $10.90^{\mathrm{a}} \pm 0.00$ \\
$>6$ & $2.47(0.069)$ \\
F-value (P-value) & $10.70^{\mathrm{a}} \pm 1.12$ \\
Trimester & $10.92^{\mathrm{a}} \pm 0.97$ \\
Second trimester & $0.713(0.49)$ \\
Third trimester & \\
F-value(P-value) & \\
Key: ab: means with similar superscripts in the same column for each \\
characteristic are not significantly different $(\mathrm{P}>0.05)$ from each other.
\end{tabular}

Table 4: Mean Haemoglobin Concentrations $(\mathrm{Hb})$ of Respondents by Educational and Income Levels and Occupation.

\begin{tabular}{ll}
\hline Variables & Haemoglobin $(\mathbf{g} / \mathbf{d l})$ \\
\hline Educational level & $10.48^{\mathrm{b}} \pm 1.07$ \\
$<$ Secondary & $10.97^{\mathrm{ab}} \pm 0.91$ \\
Secondary & $11.50^{\mathrm{a}} \pm 0.89$ \\
Tertiary & $3.676(0.030)$ \\
F-value (p-value) & \\
Income level & $10.19^{\mathrm{b}} \pm 0.76$ \\
Low (<N20,000) & $11.03^{\mathrm{a}} \pm 0.99$ \\
Medium (N20,000 - 50,000) & $11.47^{\mathrm{a}} \pm 0.64$ \\
High (>(N50,000) & \\
F-value (p-value) & $8.039(0.001)$ \\
Occupation & \\
Artisans & $9.89^{\mathrm{c}} \pm 0.86$ \\
Civil servants & $11.38^{\mathrm{a}} \pm 1.02$ \\
Farmers & $10.10^{\mathrm{bc}} \pm 0.69$ \\
Unemployed & $11.29^{\mathrm{a}} \pm 0.94$ \\
Students & $11.01^{\mathrm{ab}} \pm 1.44$ \\
Traders & $10.68^{\mathrm{abc}} \pm 0.51$ \\
F-value (P-value) & $4.295(0.002)$ \\
\hline Key: abc means with similar superscripts in the same column for each \\
characteristic are not significantly different (P >0.05) from each other. \\
\end{tabular}


Iron status of pregnant women in Nsukka

The respondents' mean haemoglobin concentrations by parity and trimester are presented in Table 3. It showed that the respondents' iron status was not significantly influenced by parity and stage of pregnancy $(\mathrm{F}=$ 2.47 and 0.713 , respectively; $\mathrm{P}>0.05$ ). Table 4 presents the respondents' mean haemoglobin concentrations by educational and income levels and occupation. It was shown that educational levels of the respondents had significant effect on their iron status. The higher the respondents' educational level, the higher their haemoglobin concentrations $(\mathrm{F}=3.676 ; \mathrm{P}<0.05)$. The results further showed that income level had significant effect on iron status of the respondents. The respondents' haemoglobin concentrations increased significantly with increase in income level $(\mathrm{F}=8.039 ; \mathrm{P}<0.05)$. The result also showed that occupation had significant effect on the respondents' haemoglobin concentrations ( $\mathrm{F}$ $=4.295 ; \mathrm{P}<0.05)$. Artisans and farmers had significantly lower mean haemoglobin concentrations $(9.89 \pm 0.86 \mathrm{~g} / \mathrm{dl}$ and $10.1 \pm$ $0.69 \mathrm{~g} / \mathrm{dl}$, respectively), followed by traders $(10.68 \pm 0.99 \mathrm{~g} / \mathrm{dl})$. Civil servants, unemployed and students had significantly higher mean haemoglobin concentrations $(11.38 \pm 1.02 \mathrm{~g} / \mathrm{dl}$, $11.29 \pm 0.94 \mathrm{~g} / \mathrm{dl}$ and $11.01 \pm 1.44 \mathrm{~g} / \mathrm{dl}$, respectively).

\section{DISCUSSION AND CONCLUSION}

The high prevalence of iron deficiency (55.9\%) among the study population accorded earlier reports of ACC/SCN (2000); FGN/UNICEF (1994). The significant low iron status of the teenagers $(8.5 \mathrm{~g} / \mathrm{dl})$ confirmed earlier observation that adolescents had poor eating habits and were known for snacking on foods which have low micronutrient densities (Ene-Obong, 2001). The influence of educational levels on the iron status of the respondents as revealed in this study was a function of increased awareness of the importance of adequate diet and what constitute a balanced diet. It has earlier been observed that the dearth of knowledge of the health and economic benefits of locally available foods precipitated faulty food choices and habits (EneObong, 2001; Okeke and Eze, 2006).

Moreover, education is linked with income which also influenced the iron status of the respondents. It is well known that the nature, quality and quantity of foods consumed are functions of income. Socio-economic status determined purchasing power as well as influenced the quality and quantity of the diet consumed (Ene-Obong, 2001). Earlier reports show that low income families were not able to purchase food items rich in haem iron such as beef, organ meat and egg which have higher bioavailability (ACC/SCN, 1990; Okeke et al., 2009; Nnanyelugo, King, Ene-Obong and Ngoddy, 1985). Economic power has been observed to be the most important determinant of women's relative equality, which affects decision making, life style options, and control over resources such as food (ACC/SCN, 1990).

The higher iron status of civil servants, the unemployed and students than artisans, farmers and traders was a function of education. Artisans, farmers and traders might not have had as much nutrition education as their educated counterparts. As for the higher iron status of the unemployed, it is also well known that in addition to nutrition education and purchasing power, proper eating/feeding demands time for meal preparation and consumption. It has been earlier observed that time constraint was a serious problem among house wives who worked long hours outside the home (EneObong, 2001). Time constraints may lead to infrequent meals, and exhaustion may lead to a reduced appetite all of which result in reduced overall intake and lower intake of individual nutrients (ACC/SCN, 1992). In conclusion, it is obvious from the results of this study that women's nutritional and health status hinge on improved educational and economic empowerment. Women's nutritional status is further impaired by early marriage and teenage pregnancy.

\section{Recommended intervention strategies}

It needs to be stated that women's education must be highly prioritized and facilitated by creating awareness of the importance of girl-child education, free education up to secondary school level, and organizing adult education for illiterate adult women. Community-based approaches should be used to reduce the prevalence of adolescent marriage/pregnancy and for promotion of girlchild education. More income generating activities/entrepreneurial skills for women are imperative to increase women's income and boost their spending on family food. These become even more pertinent when one considers that women play a major role in determining what their families eat. When women are healthy, educationally and economically empowered, their children thrive better and their entire families, communities and nations flourish and yield multiple dividends. 


\section{REFERENCES}

ACC/SCN (1990). Women and nutrition. Nutrition Policy Discussion Paper No. 6. ACC/SCN, Geneva.

ACC/SCN (1991). Controlling iron deficiency. Nutrition Policy Discussion Paper No. 9. ACC/SCN, Geneva.

ACC/SCN (1992). Women's nutritional status. Second Report on the World Nutrition, 1. ACC/SCN, Geneva.

ACC/SCN (2000). Nutrition Throughout the Life Cycle. Fourth Report on the World's Nutrition Situation. ACC/SCN in collaboration with IFPRI, Geneva.

Burtis C.A. and Ashwood E.R. (1996). Tietz Fundamentals of Clinical Chemistry. $4^{\text {th }}$ ed. W.B. Saunders, Philadelphia.

DeMaeyer et al. (1989). Preventing and Controlling Iron Deficiency Anaemia through Primary Health Care: A Guide for Health Administrators and Programme Managers. WHO, Geneva

Ene-Obong H.N. (2001). Eating Right: A Nutritional Guide. University of Calabar Press, Calabar.

Federal Ministry of Heath (2008). Integerated Maternal, Newborn and Child Health Strategy. Federal Ministry of Health, Abuja.

FGN/UNICEF (1994). The Nutritional Status of Women and Children in Nigeria. National Planning Commission, Abuja.

Harrison K.A. (1982). Anaemia, malaria, and sickle cell disease. Clinics in Obstetrics and gynaecology, 9: 445 - 447.

International Nutritional Anaemia Consultative Group (1985). Measurement of Iron Status. A Report of the International Nutritional Anaemia Consultative Group. The Nutrition Foundation Inc., Washington D.C.
Maxiya-Dixon B., Akinyele I.O., Oguntona E.B., Nokoe S., Sanusi R.A. and Harris E. (2004). Nigeria Food Consumption and Nutrition Survey 2001 - 2003. IITA, Ibadan.

National Committee for Clinical Laboratory Standards (1991). Procedures for the Collection of Diagnostic Blood Samples by Venipuncture. $3^{\text {rd }}$ ed. National Committee for Clinical Laboratory Standards, Villanova, PA.

Nnanyelugo D.O., King J., Ene-Obong H.N., Ngoddy P.O. (1985). Seasonal variation and contribution of cowpea (Vigna unguiculata) and other legumes to nutrient intake in Anambra State, Nigeria. Ecology of Food and Nutrition, 17: $271-287$

Okeke E. C., Ene-Obong H. N., Uzoegbunam A. O., Ozioko A., Umeh S. I. and Chukwuone N. (2009). The Igbo traditional food system documented in four states in Southern Nigeria. Indigenous Peoples' Food System: The Many Dimensions of Culture Diversity and Environment for Nutrition and Health. FAO, Rome.

Okeke, E.C. and Eze, C (2006). Nutrient composition and nutritive cost of Igbo traditional vendor foods and recipes commonly eaten in Nsukka. AgroScience, 5: $36-44$.

Scholl T.O. and Hediger M.L. (1994). Anaemia and iron deficiency anaemia: compilation of data on pregnancy outcome. American Journal of Clinical Nutrition, 59: 492 - 501.

Viteri F.E. (1994). The consequences of iron deficiency and anaemia in pregnancy on maternal health, the foetus and the infant. SCN News, 11: $14-18$. 